\title{
Effect of parasympathetic impairment on the haemodynamic response to handgrip in Chagas's heart disease
}

\author{
JOSÉ A MARIN-NETO, BENEDITO C MACIEL, LOURENCO GALLO JR, \\ LUIZ F JUNQUEIRA JR, DALMO S AMORIM \\ From the Cardiac Catheterisation Laboratory, Faculdade de Medicina de Ribeirão Preto, Universidade de São \\ Paulo, Brazil
}

SUMMARY Haemodynamic responses to. sustained isometric exercise (handgrip at $30 \%$ of maximum voluntary capacity) were studied in 10 patients with Chagas's cardiopathy without previous or current heart failure. Five of the patients (group 1) had profound impairment of parasympathetic control of heart rate. They had no tachycardia in response to intravenous administration of atropine and no bradycardia during phase IV of the Valsalva manoeuvre. The other five (group 2) showed normal vagal regulation of heart rate, as judged by chronotropic responses to these tests.

The heart rate change (mean (SD)) elicited by the handgrip test was significantly lower in group 1 (from $93.0(14 \cdot 1)$ to 95.0 (16.7) beats/min) than in group 2 (from $78.2(15 \cdot 8)$ to $92.8(18 \cdot 1$ ) beats/min). Pressor responses to handgrip were of similar magnitude (from $91.6(7 \cdot 8)$ to $109 \cdot 0$ $(8.0) \mathrm{mm} \mathrm{Hg}$ in group 1 and from $88.6(11.9)$ to $106.8(20.9) \mathrm{mm} \mathrm{Hg}$ in group 2). In both groups no significant change in stroke index was detected during handgrip. Cardiac index increased during handgrip from $4.0(1.2)$ to $4.8(1.3) 1 / \mathrm{min} / \mathrm{m}^{2}$ in group 2 , but there was no significant change in group 1 (from $4.9(0.7)$ to $4.8(1.1) 1 / \mathrm{min} / \mathrm{m}^{2}$ ). Changes in calculated systemic vascular resistance were significantly higher in group 1 (from 934 (175) to $1176(383) \mathrm{dyn} \mathrm{s} \mathrm{cm}^{-5}$ ) than in group 2 (from 1109 (404) to 1112 (424).

This study shows that parasympathetic impairment adversely influences the haemodynamic pattern of response to isometric exercise in patients with Chagas's heart disease. In such conditions, the pressor response to handgrip is predominantly mediated by an increase in systemic vascular resistance rather than an increase in cardiac output.

In normal subjects sustained isometric muscular contractions produce significant increases in heart rate, cardiac output, and systemic arterial pressure. ${ }^{1-5}$ The increase in cardiac output elicited by isometric exercise is dependent upon the concomitant chronotropic response, since no detectable change in stroke volume is usually seen during this kind of effort. ${ }^{167}$ On the other hand, the

Requests for reprints to Dr José Antonio Marin Neto, Cardiac Catheterisation Laboratory, Faculdade de Medicina de Ribeirão Preto, Universidade de São Paulo, 14.100 Ribeirão Preto, Brazil.

Accepted for publication 14 September 1985 rise in arterial pressure is directly proportional to the increase in cardiac output, with no appreciable change occurring in calculated systemic vascular resistance. $^{57}$

Parasympathetic withdrawal is the efferent mechanism responsible for the initial rise in heart rate that occurs in response to isometric exercise. ${ }^{3-11}$ Although it has not been identified in some studies, ${ }^{812}$ sympathetic stimulation makes a later contribution to the chronotropic response; the adrenergic mechanism has been detected as early as 10 seconds after the beginning of handgrip exercise at $75 \%$ of maximum voluntary capacity, ${ }^{11}$ and after 30 seconds of isometric exercise at $30 \%$ of maximum voluntary capacity. ${ }^{7}$ 
Isometric exercise has been used to evaluate the chronotropic effects on cardiac grafts ${ }^{13}$ and for the assessment of autonomic disturbances in diseases such as hypertension, ${ }^{14}$ diabetes mellitus, ${ }^{15-17}$ and congestive cardiomyopathy. ${ }^{18}$ No studies, however, have been carried out to assess the overall haemodynamic consequences of impaired cardiovascular responses to isometric exercise in diseases in which there is a primary autonomic disturbance.

Chagas's disease is well known for its unique involvement of the cardiac parasympathetic system in the absence of myocardial failure. ${ }^{19-25}$ We have evaluated haemodynamic performance during isometric exercise in chagasic patients known to have parasympathetic impairment of heart rate control, and we have compared their responses with those of chagasic patients without impaired autonomic control.

\section{Patients and methods}

\section{PATIENTS}

The study was performed in 10 selected male patients with chronic Chagas's heart disease, after they had given their written consent and the study had been approved by the hospital. All had positive complement fixation tests and the electrocardiographic changes typical of heart involvement in Chagas's disease. No patient was in heart failure or had a history of heart failure. Patients were selected on the basis of their response to an intravenous injection of atropine $(0.04 \mathrm{mg} / \mathrm{kg}$ body weight) given at the rate of $1 \mathrm{mg} / \mathrm{min}$, while the patient was supine. We selected five patients (aged 19-44, mean 30 years) in whom the heart rate did not increase after atropine (group 1), and five patients (aged 30-46, mean 38) in whom there was the expected tachycardia in response to atropine (group 2). There was slight cardiomegaly (transverse cardiothoracic index 0.51-0.53) in four patients in group 1 , who also showed clinical signs of megaoesophagus or megacolon or both. This kind of chagasic involvement of hollow viscera was also diagnosed in four patients in group 2. Four patients in group 1 and three in group 2 were in class II of the New York Heart Association criteria (1973) and the others were in class I. All patients were in sinus rhythm, and none was on any drugs capable of interfering with cardiac function. Clinical hypertension was also excluded in every case.

\section{Methods}

Each patient was first familiarised with the calibrated spring-type handgrip dynamometer and the maximum voluntary instantaneous contraction of the dominant arm was determined. After local anaesthesia, a Cournand 7F cardiac catheter was introduced by cutdown into the contralateral basilic vein, and advanced under fluoroscopic control to the right atrium. A 19 G indwelling Cournand needle was placed in the right femoral artery by percutaneous puncture under local anaesthesia.

A standard lead of the electrocardiogram, the systemic arterial pressure, and respiratory chest motions were continuously monitored and recorded in a MR-105 Waters Polygraph. The zero reference level was set in the mid-chest anteroposterior position at the third intercostal space for the P23 Gb Statham strain-gauge manometer. The respiratory cycles were recorded through a pneumograph belt connected to a P23 AA Statham strain-gauge that was also used for measuring oral pressure during the Valsalva manoeuvre. Dilution curves were determined by injection of $5 \mathrm{mg}$ of indocyanine green dye into the right atrium and continuous sampling of arterial blood through a Waters fast dynamic response densitometer. Cardiac output was determined by the Hamilton method, after

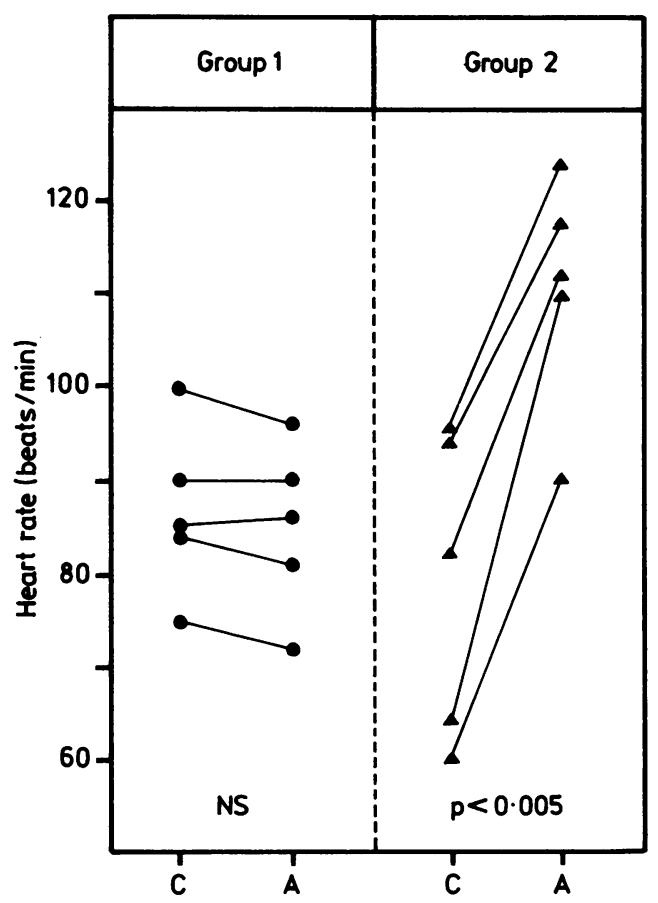

Fig. 1 Effect of intravenous atropine $(0.04 \mathrm{mg} / \mathrm{kg}$ body weight) on resting heart rate of patients with chagasic myocarditis. Only group 2 patients showed tachycardia after atropinisation $(A)$. (C) control values. $p<0.005$, Student's $t$ test for paired samples. NS, not significant. 
Table 1 Systemic arterial pressure (systolic and diastolic, $\mathrm{mm} \mathrm{Hg}$ ) and heart rate (beats/min) during baseline and the strain and recovery phases of Valsalva manoeuvre in chagasic patients with (group 1) and without parasympathetic impairment (group 2)

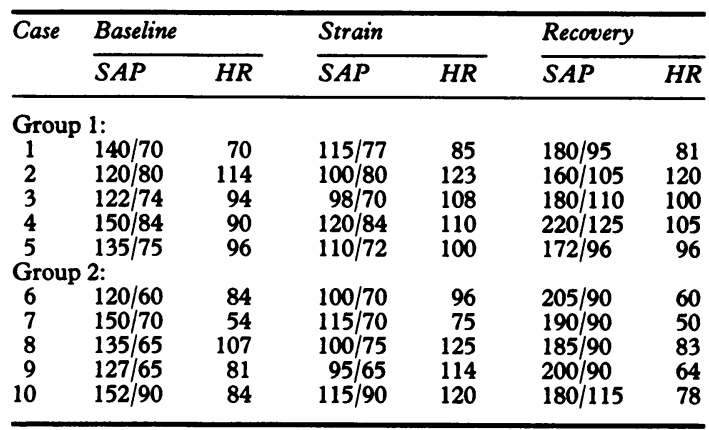

SAP, systemic arterial pressure (mm $\mathrm{Hg}) ; \mathrm{HR}$, heart rate (beats/min).

calibration of the densitometer with known concentrations of dye in blood samples of each patient.

The studies were carried out in a temperature-regulated room $\left(22-24^{\circ} \mathrm{C}\right)$ with the patients either fasting or in the postabsorptive state after a light meal.

The experimental protocol started with each patient performing a standard Valsalva manoeuvre; the oral pressure was raised suddenly to $40 \mathrm{~mm} \mathrm{Hg}$ and kept constant for about 20 seconds. Continuous recording of electrocardiogram, systemic blood pressure, and oral pressure was obtained before, during strain, and 20 seconds after release of the strain.

Five minutes after the end of the standard test baseline recordings were obtained and then the patients performed a sustained handgrip at $30 \%$ of maximum voluntary capacity for two minutes. In the last half of the exercise period, dilution curves were again obtained, and arterial pressure was immediately measured. We made certain that patients maintained normal respiration during exercise, so that inadventent performance of the Valsalva manoeuvre was avoided.

Heart rate was counted for intervals of 10 seconds during the recording of dilution curves in the baseline and handgrip periods, as well as before, during, and after the Valsalva manoeuvre. Mean systemic arterial pressure (MSAP) was recorded by electronic damping of pulse contours. Systemic vascular resistance (SVR) was derived from the formula-SVR $=$ MSAP $\times 80 /$ cardiac output.

\section{STATISTICAL ANALYSIS}

Values of variables measured during handgrip were compared with baseline values in each group by Student's paired $t$ test. The statistical significance of differences in changes evoked by handgrip, between the two groups, was assessed by unpaired Student's $t$ test. $P$ values $<0.05$ were regarded as significant.

\section{Results}

\section{CHRONOTROPIC RESPONSES TO ATROPINE}

Fig. 1 shows that in all patients in group 1 heart rate did not increase in response to atropine (individual changes were $-3,-4,+1,-3$, and 0 beats $/ \mathrm{min}$ ). In group 2 patients atropine induced pronounced tachycardia in all cases (individual changes were $+46,+30,+28,+30$, and +24 beats $/ \mathrm{min}$ ).

Table 2 Haemodynamic variables at rest and during the second minute of isometric exercise in chagasic patients with (group 1) and without parasympathetic impairment (group 2)

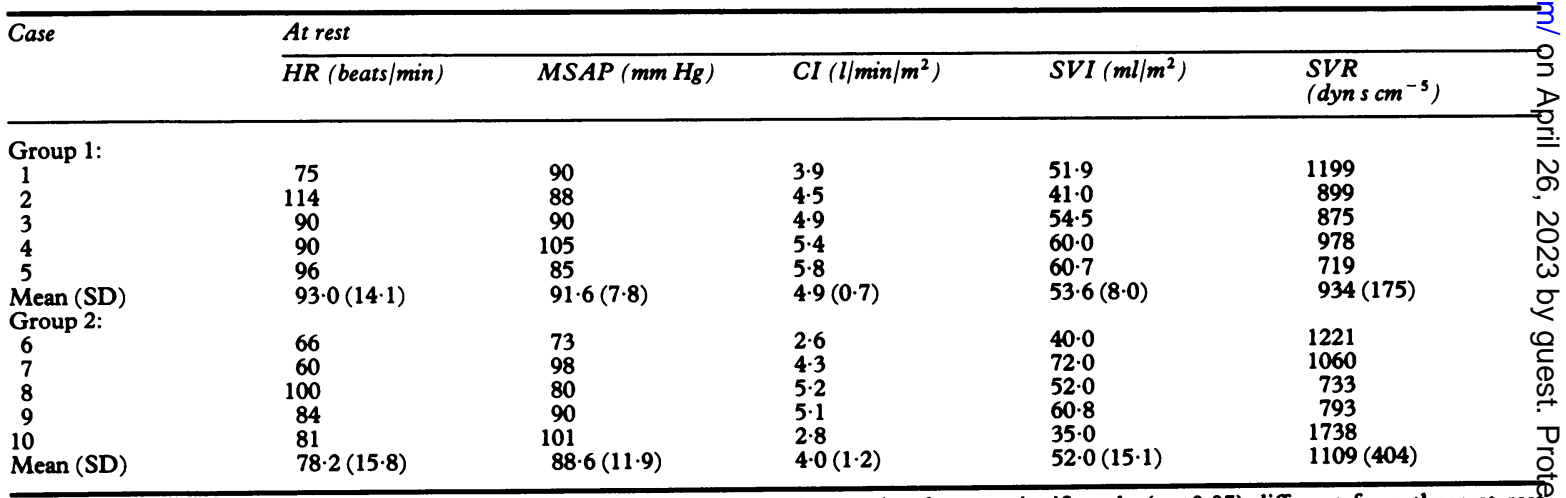

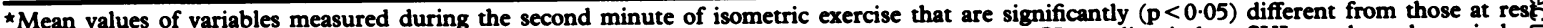
(Student's $t$ test for paired values). HR, heart rate; MSAP, mean systemic arterial pressure; CI, cardiac index; SVI, stroke volume index SVR, systemic vascular resistance. 
HEART RATE AND BLOOD PRESSURE RESPONSES DURING THE VALSALVA MANOEUVRE

Table 1 shows that in both groups there was a pronounced overshoot in blood pressure after the release of the strain. Only patients in group 2, however, had a prompt reflex bradycardia occurring in the first 20 seconds after the end of the strain. Patients in group 1 did not show cardiac slowing below baseline heart rate in the first 20 seconds after the Valsalva manoeuvre.

\section{HAEMODYNAMIC RESPONSES TO ISOMETRIC EXERCISE}

Table 2 shows that handgrip at $30 \%$ of maximal voluntary capacity induced a significant increase in mean (SD) heart rate in group 2 only (from 78.2 $(15.8)$ to $92.8(18.1)$ beats/minute $(+18.7 \%$, $\mathrm{p}<0.05))$. There was a similar increase in systemic arterial pressure in both groups (from $91.6(7.8)$ to $109.0(8.0) \mathrm{mm} \mathrm{Hg}(+19.0 \%, \mathrm{p}<0.001)$ in group 1 and from $88.6(11.9)$ to $106.8(20.9) \mathrm{mm} \mathrm{Hg}$ (+ $20.5 \%, \mathrm{p}<0.05$ ) in group 2 ).

In group 1 there was no significant change in the mean cardiac index. In group 2 cardiac index rose from $4.0(1.2)$ to $4.8(1.3) 1 / \mathrm{min} / \mathrm{m}^{2}(+20.0 \%$, $\mathrm{p}<0.005)$. No significant changes in stroke volume index were found in either group. In contrast, the calculated systemic vascular resistance was higher during handgrip than at baseline in group 1 (from 934 (175) to $1176(383)$ dyn s $\left.\mathrm{cm}^{-5}\right)(+25.9 \%$, $\mathrm{p}<0.025)$ but not in group 2 .

Fig. 2 shows the changes in heart rate, systemic arterial pressure, cardiac index, and systemic vascular resistance that were elicited by handgrip. Group 2 patients showed significantly greater

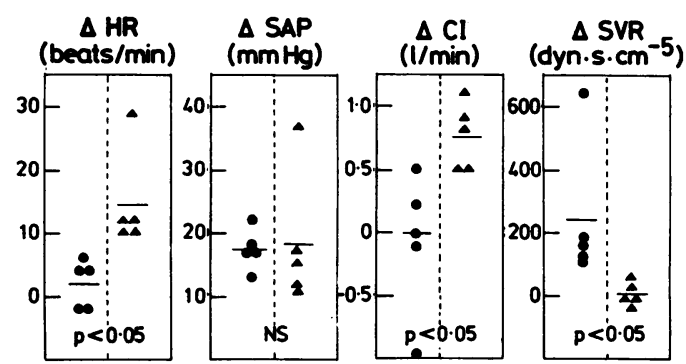

Fig. 2 Changes in heart rate $(\Delta H R)$, mean systemic arterial pressure $(\triangle S A P)$, cardiac index $(\Delta C I)$, and systemic vascular resistance $(\Delta S V R)$ evoked by handgrip at $30 \%$ of maximal voluntary capacity in chagasic patients with (circles) and without parasympathetic impairment (triangles). Statistical significance was assessed by Student's $t$ test for unpaired samples.

$(p<0.05)$ increases in heart rate and cardiac index than patients in group 1. Increases of mean blood pressure were similar in both groups, whereas changes in systemic vascular resistance were significantly higher in group $1(p<0.05)$.

\section{Discussion}

These results clearly show that there is a distinctive pattern of haemodynamic responses to handgrip at $30 \%$ of maximum voluntary capacity in chagasic patients in whom parasympathetic modulation of heart rate is absent (group 1). In these patients the pressor response to isometric exercise is mediated by an increase in systemic vascular resistance. In contrast, chagasic patients with intact parasympathetic control (group 2) showed

\begin{tabular}{|c|c|c|c|c|}
\hline \multicolumn{5}{|c|}{ During handgrip test } \\
\hline$\overline{H R \text { (beats/min) }}$ & $M S A P(m m ~ H g)$ & $C I\left(l / \min / m^{2}\right)$ & $S V I\left(m l / m^{2}\right)$ & $S V R\left(d y n \mathrm{scm}^{-5}\right)$ \\
\hline $\begin{array}{l}73 \\
120 \\
94 \\
94 \\
94 \\
95 \cdot 0(16 \cdot 7)\end{array}$ & $\begin{array}{l}103 \\
110 \\
108 \\
122 \\
102 \\
109 \cdot 0(8 \cdot 0)^{\star}\end{array}$ & $\begin{array}{l}2.9 \\
5.0 \\
4.9 \\
5.6 \\
5.7 \\
4.8(1 \cdot 1)\end{array}$ & $\begin{array}{l}40.2 \\
41.7 \\
52.5 \\
59.6 \\
61.9 \\
51.2(10.0)\end{array}$ & $\begin{array}{l}1845 \\
1011 \\
1050 \\
1097 \\
878 \\
1176(383)\end{array}$ \\
\hline $\begin{array}{l}76 \\
72 \\
110 \\
96 \\
110 \\
92 \cdot 8(18 \cdot 1)^{\star}\end{array}$ & $\begin{array}{l}84 \\
115 \\
95 \\
102 \\
138 \\
106 \cdot 8(20 \cdot 9)^{\star}\end{array}$ & $\begin{array}{l}3 \cdot 1 \\
5 \cdot 1 \\
6 \cdot 3 \\
5.6 \\
3 \cdot 7 \\
4 \cdot 8(1 \cdot 3)^{\star}\end{array}$ & $\begin{array}{l}41 \cdot 3 \\
70 \cdot 3 \\
57 \cdot 3 \\
58 \cdot 4 \\
32 \cdot 0 \\
51.9(15 \cdot 2)\end{array}$ & $\begin{array}{l}1178 \\
1049 \\
718 \\
819 \\
1798 \\
1112(424)\end{array}$ \\
\hline
\end{tabular}


haemodynamic responses that were similar to those described in normal subjects ${ }^{7627}$ in whom the pressor response is mediated by increase in cardiac output.

We found that the haemodynamic response in chagasic patients with impairment of the parasympathetic influences on the sinus node was substantially different from that seen in normal volunteers in whom the response was blocked with atropine. The normal volunteers maintained increases in cardiac output and arterial pressures. ${ }^{7}$ Although the body position and the magnitude of isometric exercise $30 \%$ of maximum voluntary capacity) were the same in both studies, Martin et al measured haemodynamics in the third minute of handgrip rather than in the second minute as we did in this study. It has been suggested that the heart rate and the cardiac output may not stabilise completely when the isometric exercise is performed at higher levels of muscle tension. ${ }^{128}$ Furthermore, Martin et al gave fixed doses of $2.0 \mathrm{mg}$ of atropine to their subjects, a dose that in some individuals might have been well below the $0.04 \mathrm{mg} / \mathrm{kg}$ body weight recommended for effective blockade of the parasympathetic system. ${ }^{29} 30$ These differences may explain why after atropine Martin et al found that their normal volunteers still had a substantial mean heart rate increase of 12 beats/minute and an average increase of $650 \mathrm{ml}$ in cardiac output. ${ }^{7}$ Apart from the fact that short term pharmacological blockade may not entirely reproduce the effects of chronic interruption of vagal efferents that is seen in Chagas's disease, parasympathetic withdrawal may have contributed to the chronotropic responses to handgrip seen in the subjects studied by Martin et $a .^{7}$ As a consequence, the pressor response still made an important contribution to the increase in cardiac output. Nevertheless, as in our group 1 of chagasic patients, the systemic vascular resistance increased in 10 of 12 normal subjects who performed handgrip after administration of atropine. ${ }^{7}$

Chagasic patients in group 1 undoubtedly had no parasympathetic regulation of sinus node function. Not only was heart rate reflexly unresponsive to an increase of blood pressure after the performance of the Valsalva manoeuvre, but there was also no resting vagal tonus acting upon the sinus node, as was demonstrated by the lack of chronotropic changes after atropine. Therefore, it is conceivable that parasympathetic impairment, which is the hallmark of cardiac autonomic disturbances in Chagas's disease both in anatomical ${ }^{31-33}$ and functional terms, ${ }^{19-2534}$ was responsible for the abnormal cardiovascular response to isometric exercise. Whether there is concomitant impairment of sympathetic system mediated control of heart rate in chagasic patients is debatable. In some studies in which the response to passive postural stimulation was studied adrenergic control of heart rate was shown to be deficient, ${ }^{22} 23$ but other results derived from tests that elicit higher degrees of stimulation such as dynamic exercise ${ }^{2135}$ militate against this possibility. The findings of the present work do not exclude impairment of the sympathetic control of the sinus node as a minor contributory factor to the abnormal haemodynamic responses to handgrip seen in group 1. Unaltered pressor responses to handgrip were seen after propranolol ${ }^{736}$; however, no change in cardiac output was seen, and the pressure rise depended upon an increase in systemic vascular resistance. On the other hand our findings confirm the normal sympathetic control of vascular tone in chagasic patients, as already shown in previous studies. ${ }^{202223}$

Having showed that in some chagasic patients an increase of systemic vascular resistance rather than an increase in cardiac output mediates blood pressure rise during isometric exercise, it is interesting to speculate about the functional consequences of such haemodynamic alterations. Because isometric exercise is common during daily active life, these patients must face frequent afterload challenges that do not arise when chronotropic responses are normal. The situation resembles that in untreated hypertensive patients. ${ }^{14} 37$. Our patients had neither systemic hypertension nor demonstrable clinical reduction in myocardial reserve. As the disease progresses, however, left ventricular function may become abnormal in chagasic patients. Studies in ischaemic heart disease, 262738 and in other myocardial diseases, ${ }^{26273839}$ show that although the heart rate response is impaired the pressor response to isometric exercise may even be potentiated when there is left ventricular dysfunction. Moreover, isometric exercise has been recently shown to disclose abnormal left ventricular function in chagasic patients with otherwise normal performance at rest. ${ }^{40}$ Therefore, it seems reasonable to conclude that chagasic patients with impaired parasympathetic responses have less effective left ventricular ejection during their customary activities than do individuals who are capable of normal heart rate responses to isometric exercise. Such functional abnormalities could increase the chronic stresses imposed on left ventricular performance. No demonstrable correlation has been shown between autonomic impairment and myocardial depression in Chagas's disease, and a prospective follow up study is now underway in our laboratory to evaluate the effect of autonomic disturbances on the development of 
ventricular dysfunction and outcome in patients with Chagas's heart disease.

This research was partly supported by grants of the Conselho Nacional de Desenvolvimento Cientifico e Technológico.

\section{References}

1 Lind AR, Taylor SH, Humphreys PW, Kennelly BM, Donald KW. The circulatory effects of sustained voluntary muscle contraction. Clin Sci 1964; 27: 229-44.

2 Lind AR. Cardiovascular responses to static exercise. Circulation 1970; 41: 173-6.

3 Nutter DO, Schlant RC, Hurst JR. Isometric exercise and the cardiovascular system. Mod Concepts Cardiovasc Dis 1972; 41: 11-5.

4 Mitchell JH, Wildenthal K. Static (isometric) exercise and the heart: physiological and clinical considerations. Annu Rev Med 1974; 25: 369-81.

5 Ludbrook J. Reflex control of blood pressure during exercise. Annu Rev Physiol 1983; 45: 155-68.

6 Lind AR, McNicol GW. Muscular factors which determine the cardiovascular responses to sustained and rhythmic exercise. Can Med Assoc f 1967; 96: 706-13.

7 Martin CE, Shaver JA, Leon DF, Thompson ME, Reddy PS, Leonard JJ. Autonomic mechanisms in hemodynamic responses to isometric exercise. $f$ Clin Invest 1974; 54: 104-15.

8 Freyschuss U. Cardiovascular adjustment to somatomotor activation: elicitation of increments in heart rate, aortic pressure and venomotor tone with the initiation of muscle contraction. Acta Physiol Scand 1970; (suppl 342): 1-63.

9 Freyschuss U. Elicitation of heart rate and blood pressure increase on muscle contraction. $\mathrm{f}$ Appl Physiol 1970; 28: 758-61.

10 Petro JK, Hollander AP, Bouman LN. Instantaneous cardiac acceleration in man induced by a voluntary muscle contraction. I Appl Physiol 1970; 29: 794-8.

11 Maciel BC, Gallo L Jr, Marin-Neto JA, Amorim DS, Manço JC. Autonomic regulation of heart rate during exercise (dynamic and isometric) [Abstract]. In: Proceedings of the Second Panamerican Congress of Diseases of the Chest, Rio de Janeiro, 1980:25-6.

12 MacDonald HR, Sapru RP, Taylor SH, Donald KW. Effects of intravenous propranolol on the systemic circulatory response to sustained handgrip. Am $\mathcal{f}$ Cardiol 1966; 18: 333-44.

13 Haskell WL, Savin WM, Schroeder JS, et al. Cardiovascular responses to handgrip isometric exercise in patients following cardiac transplantation. Circ Res 1981; 48 (suppl 1): 156-61.

14 Ewing DJ, Irving JB, Kerr F, Kirby BJ. Static exercise in untreated systemic hypertension. Br Heart $\mathcal{F}$ 1973; 35: 413-21.

15 Ewing DJ, Irving JB, Kerr F, Wildsmith JAW, Clarke BF. Cardiovascular responses to sustained hand grip in normal subjects and in patients with diabetes mellitus: a test of autonomic function. Clin $S c i$ 1974; 46:
295-306.

16 Nazar K, Taton J, Chwalbinska-Moneta J, Brzezinka $\mathrm{Z}$. Adrenergic responses to sustained hand grip in patients with juvenile onset-type diabetes mellitus. Clin Sci 1975; 49: 39-44.

17 Hume L, Ewing DJ, Campbell IW, Reuben SR, Clarke BF. Heart-rate response to sustained hand grip: comparison of the effects of cardiac autonomic blockade and diabetic autonomic neuropathy. Clin Sci 1979; 56: 287-91.

18 Amorim DS, Dargie $\mathrm{H}$, Heer $\mathrm{K}$, et al. Is there autonomic impairment in congestive (dilated) cardiomyopathy? Lancet 1981 ; i: 525-7.

19 Amorim DS, Godoy RA, Manço JC, Tanaka A, Gallo $\mathrm{L} \mathrm{Jr}$. Effects of acute elevation in blood pressure and of atropine on heart rate in Chagas' disease. Circulation 1968; 38: 289-94.

20 Manço JC, Gallo L Jr, Godoy RA, Fernandes RG, Amorim DS. Degeneration of the cardiac nerves in Chagas' disease. Circulation 1969; 40: 879-85.

21 Gallo L Jr, Marin Neto JA, Manço JC, Rassi A, Amorim DS. Abnormal heart rate responses during exercise in patients with Chagas' disease. Cardiology 1975; 60: $147-62$.

22 Marin Neto JA, Gallo L Jr, Manço JC, Rassi A, Amorim DS. Postural reflexes in chronic Chagas' heart disease. Cardiology 1975; 60: 343-57.

23 Marin Neto JA, Gallo L Jr, Manço JC, Rassi A, Amorim DS. Mechanisms of tachycardia on standing: studies in normal individuals and in chronic Chagas' heart patients. Cardiovasc Res 1980; 14: 541-50.

24 Amorim DS, Manço JC, Gallo L Jr, Marin-Neto JA. Chagas' heart disease as an experimental model for studies of cardiac autonomic function in man. Mayo Clin Proc 1982; 57 (suppl): 48-60.

25 Junqueira LF Jr, Gallo L Jr, Manço JC, Marin Neto JA, Amorim DS. Subtle cardiac autonomic impairment in Chagas' disease detected by baroreflex sensitivity testing. Braz $\mathcal{F}$ Med Biol Res 1985; 18: 171-8.

26 Helfant RH, de Villa MA, Meister SG. Effect of sustained isometric handgrip exercise on left ventricular performance. Circulation 1971; 44: 982-93.

27 Quinones MA, Gaasch WH, Waisser E, Thiel HG, Alexander JK. An analysis of the left ventricular response to isometric exercise. Am Heart $\mathcal{f}$ 1974; 88: 29-36.

28 Donald $\mathrm{KW}$, Lind AR, McNicol GW, Humphreys PW, Taylor SH, Stauton HP. Cardiovascular responses to sustained static contractions. Circ Res 1967; 20 (suppl 1): $15-30$

29 Jose AD. Autonomic blockade by propranolol and atropine to study intrinsic myocardial function in man. $\mathcal{J}$ Clin Invest 1969; 48: 2019-31.

30 Maciel BC, Gallo L Jr, Marin-Neto JA, Terra-Filho J, Manço JC. Pharmacological blockade of the cardiac parasympathetic system with atropine: efficacy and duration. Braz f Med Biol Res 1985; 18: 303-8.

31 Köberle F. Enteromegaly and cardiomegaly in Chagas' disease. Gut 1963; 4: 399-405.

32 Mott KE, Hagstrom JWC. The pathologic lesions of the cardiac autonomic nervous system in chronic Chagas' myocarditis. Circulation 1965; 31: 273-86. 
33 Oliveira JSM, de Oliveira JAM, Frederigue U Jr, Lima-Filho EC. Apical aneurysm of Chagas' heart disease. Br Heart $f$ 1981; 46: 432-7.

34 Amorim DS, Oliveira JAM, Manço JC, Gallo L Jr, Oliveira JSM. Chagas' heart disease. First demonstrable correlation between neuronal degeneration and autonomic impairment. Acta Cardiol (Brux) 1973; 28: 431-40.

35 Morelo-Filho J, Gallo L Jr, Maciel BC, et al. Cardiorespiratory adjustments during dynamic exercise in normal subjects and in chronic chagasic patients [Abstract]. Braz F Med Biol Res 1984; 17: 442.

36 Watt SJ, Thomas RD, Belfield PW, Goldstraw PW, Taylor SH. Influence of sympatholytic drugs on the cardiovascular response to isometric exercise. Clin Sci 1981 ; 60: $139-43$.
37 Hoel BL, Lorentsen E, Lund-Larsen PC. Haemodynamic responses to sustained handgrip in patients with hypertension. Acta Med Scand 1970; 188: 491-8.

38 Fisher ML, Nutter DO, Jacobs W, Schlant RC. Haemodynamic responses to isometric exercise (handgrip) in patients with heart disease. Br Heart $\mathcal{f}$ 1973; 35: 422-32.

39 Perez-Gonzales JF, Schiller NB, Parmley WW. Direct and noninvasive evaluation of the cardiovascular response to isometric exercise. Circ Res 1981; 48 (suppl 1): 138-48.

40 Galiano NE, Estudo da reserva cardiaca em pacientes assintomáticos portadores da doença de Chagas na sua forma crônica, submetidos ao exercício isométrico contínuo. Ribeirão Preto (SP): Universidade de São Paulo, 1983. Thesis. 